DOI: https://doi.org/10.30749/2177-8337.v24n49p157-172

\title{
CONTROLE JUDICIAL DAS POLÍTICAS PÚBLICAS E NECROPOLÍTICA NO RIO DE JANEIRO EM TEMPOS DE COVID-19
}

\section{JUDICIAL CONTROL OF PUBLIC POLICIES AND NECROPOLITICS IN RIO DE JANEIRO IN TIMES OF COVID-19}

\author{
Larissa Gabriela Cruz Botelho* \\ Joyce Abreu de Lira**
}

Resumo: $O$ trabalho investiga a necropolítica enquanto ação estatal jurídica, política e socialmente violadora da dignidade humana. Em outras palavras, a adoção da violência estatal como política pública e os seus resultados antijurídicos e ilícitos. 0 desenvolvimento da pesquisa tem por objeto o cotejo aos fatos contidos na ADPF 635, bem como o levantamento de dados quantitativos, a serem transversalizados com a teoria crítica de Achille Mbembe e Foucault, quanto à instrumentalização do poder na estrutura estatal com o objetivo de perseguição de inimigos desse mesmo poder. Sendo assim, um trabalho com metodologia mista, reunindo de forma indutiva os dados da realidade com a análise teórica e crítica da ação estatal, por meio de suas políticas públicas de segurança e dos respectivos resultados.

Palavras-chave: Políticas Públicas. Segurança Pública. Necropolítica.

Abstract: The work investigates the necropolitics as a legal, political and socially violating state action of human dignity. In other words, the adoption of state violence as a public policy and its anti-legal and illicit results. The research development aims to compare the facts contained in ADPF 635, as well as the survey of quantitative data, to be transversalized with the critical theory of Achille Mbembe and Foucault, regarding the instrumentalization of power in the state structure with the objective of persecution enemies of that same power. Therefore, it is a work with mixed methodology, bringing together the data of reality with the theoretical and critical analysis of state action, through its public security policies and the respective results.

Keywords: War on Drugs. Public Security. Necropolitics.

Recebido em: 01/10/2020. Aceito em: 08/10/2020.

\footnotetext{
* Mestra em Direito Penal pela Universidade do Estado do Rio de Janeiro. Professora da Universidade Veiga de Almeida. E-mail: lari_gcb@hotmail.com.

** Doutoranda no Programa de Pós-Graduação em Direitos, Instituições e Negócios na Universidade Federal Fluminense. Mestra pelo Programa de Pós-Graduação em Direito Constitucional na Universidade Federal Fluminense. Professora da Universidade Veiga de Almeida. Pesquisadora no Grupo de Pesquisa em Direitos Fundamentais da Universidade Federal Fluminense. E-mail: joyce.lira@gmail.com.
} 


\section{INTRODUÇÃO}

A Ação de Descumprimento de Preceito Fundamental proposta pelo Partido Socialista Brasileiro questiona dois artigos de decretos estaduais do estado do Rio de Janeiro. O primeiro deles é a permissão para utilização de helicópteros como plataforma de tiro em apoio a operações da polícia militar. O segundo foi a retirada do cálculo das gratificações a batalhões e delegacias os indicadores de baixa letalidade policial.

Tanto o uso de helicópteros quanto a retirada das gratificações referentes à baixa letalidade são um grande estímulo ao confronto policial na guerra às drogas. A política pública de guerra às drogas, cujo modelo é importado dos Estados Unidos, tem provocado um superencarceramento de jovens, pretos e pobres, e tem vitimado essa mesma população pelas inúmeras operações policiais.

Em outras palavras, o desenho da política de combate às drogas não encontra os resultados teoricamente esperados, o que ocorre por inúmeros fatores. Por outro lado, essa mesma ação estatal produz outros resultados, os quais, após décadas de repetição de padrões de ação, evidentemente já passaram a ser parte dos próprios objetivos do Estado. É inegável se uma determinada ação se repete produzindo sempre os mesmos resultados, a opção por manter o modelo dessa política significa a inclusão dos seus resultados na própria estrutura da administração do problema público. E o pior, o resultado dessa política pública gera outras questões públicas.

O problema da violência institucional, da política de encarceramento e genocídio do povo pobre e preto encontra um aprofundamento ainda maior em meio aos eventos de força maior que assolam esses grupos de indivíduos. Com a declaração da pandemia de coronavírus pela Organização Mundial da Saúde em março de 2020, as incursões policiais nas favelas do Rio de Janeiro até diminuíram, num primeiro momento, mas retornaram em maio do mesmo ano, com muita intensidade e vitimando ainda mais pessoas se comparado ao mesmo período de 2019.

Diante desse quadro generalizado de violações de direitos humanos, questiona-se se a guerra às drogas não seria um projeto de Estado. A questão se coloca quando se constata que a dita guerra não surtiu os efeitos supostamente pretendidos, quais sejam, o fim do tráfico de drogas e do uso das substâncias 
psicotrópicas ilícitas. Então, pergunta-se, por que persistir na lógica do confronto? Não há uma resposta explícita para a questão, mas existem explicações possíveis e, dentre elas, encontra-se a ideia de necropolítica.

Nesse contexto, a pretensão deste trabalho é investigar sobre a manutenção dos resultados negativos da política de segurança pública no contexto pandêmico do Rio de Janeiro, cotejando-a com o controle judicial da política pública em questão. A partir do levantamento dos dados empíricos, atravessando-os pelo ponto de vista teórico, busca-se compreender o motivo pelo qual as mortes decorrentes de intervenção policial continuaram altas, inclusive nos tempos de pandemia, e em que medida isso faz parte das escolhas públicas na gestão da política de segurança pública no Rio de Janeiro.

Em outros termos, como questões norteadoras, investigar se a interferência do STF na política de segurança pública teria alterado esse quadro de letalidade policial e se a proibição de incursão em favelas no Rio de Janeiro teria diminuído o número de mortes. Se a resposta ao questionamento for sim, como a hipótese levantada, o que se percebe é que a polícia do Estado seria mais letal que a própria traficância cotidiana, a qual, discursivamente, pretende-se combater. A partir dessa hipótese preliminar é possível um diagnóstico também preliminar: a política de segurança pública é um projeto de morte daqueles que Mbembe aponta como os matáveis (MBEMBE, 2018).

A pesquisa, assim, desenvolve-se indutivamente, partindo dos dados quantitativos coletados para a construção de interseção com as reflexões teóricas e críticas apresentadas tanto na perspectiva jurídica, como na sociológica e na política. A revisão bibliográfica parcialmente exploratória desses campos do saber, de forma transversal e multidisciplinar, é utilizada como ferramenta principal, em conjunto com o levantamento de dados já mencionado. Sendo assim, trata-se de pesquisa sociojurídica ou empírico-jurídica, transversalizada ao campo das políticas públicas.

As políticas públicas são fenômenos recentes no campo científico, portanto o trabalho pretende colaborar, também, para ampliação dos estudos e das reflexões metodológicas para compreender tais categorias de análise dentro dos já muito debatidos assuntos que interligam o direito e a sociologia. É certo que, de alguma maneira, o ponto de interseção dos campos consiste justamente na teoria do Estado (MULLER, 2018) e na compreensão da sua racionalidade, funcionalidade e atividade. 
Assim, os resultados esperados com a pesquisa consistem no levantamento de dados quantitativos dos investimentos e dos resultados das políticas de segurança pública, a serem cotejados com o objeto jurídico e sociológico decorrente da análise de elementos da ADPF 635, de modo a construir uma compreensão crítica acerca da necropolítica enquanto ação do Estado, jurídica, política e socialmente violadora da dignidade humana.

\section{A ADPF 635 E A PANDEMIA DO NOVO CORONAVÍRUS}

O alto número de mortes de crianças e adolescentes no Rio de Janeiro no ano de $2019^{1}$ motivou a propositura de Ação de Descumprimento de Preceito Fundamental (ADPF) no dia 19 de novembro de 2019, pelo Partido Socialista Brasileiro. A ação ajuizada revelou o agravamento da letalidade policial no Estado do Rio de Janeiro, notadamente em áreas periféricas (SARMENTO et al., 2019). Consequentemente, o que se revela é a falha na gestão das políticas públicas de segurança no Estado, cujos resultados negativos persistiram mesmo durante o cenário pandêmico.

A petição inicial da ADPF propôs o reconhecimento da inconstitucionalidade dos seguintes pontos relativos à segurança pública do Rio de Janeiro, quais sejam: i) declarar a inconstitucionalidade do Art. $2^{\circ}$ do Decreto Estadual 27.795/2001 (RIO DE JANEIRO, 2001), de modo a vedar o uso de helicópteros como plataforma de tiro; ii) e declarar a inconstitucionalidade do art. $1^{\circ}$ do Decreto Estadual n 46.775/2019 (RIO DE JANEIRO, 2019), de modo a reinserir, no cálculo das gratificações dos integrantes de batalhões e delegacias, os indicadores de redução de homicídios decorrentes de oposição à intervenção policial. (SARMENTO et al., 2019).

Segundo dados apresentados na petição inicial da ADPF 635 (SARMENTO et al., 2019), apenas nos primeiros nove meses do ano de 2019 houve um incremento de $18,5 \%$ em relação ao mesmo período do ano de 2018. A maioria dos mortos são negros moradores de regiões periféricos no estado do Rio.

\footnotetext{
${ }^{1}$ A petição inicial do Partido Socialista Brasileiro (PSB), na ADPF 635, faz menção às mortes de Ágatha Vitória Félix (8 anos), Jenifer Silene Gomes (11 anos), Kauan Peixoto (12 anos), Kauã Rozário (11 anos), Kauê Ribeiro dos Santos (12 anos) e Kelvin Gomes (17 anos) todos mortos em operações policiais no Rio de Janeiro.
} 
O Rio de Janeiro é o Estado da federação cujas forças de segurança mais matam no país: somente em 2018, foram 1.534 mortes provocadas por policiais. São Paulo e Bahia ocupam o segundo e terceiro lugar com 851 e 794 mortes, respectivamente. (SARMENTO et al., 2019, p. 4).

Só a polícia fluminense é responsável por $23 \%$ das mortes violentas ocorridas em todo território brasileiro em 2018. O indicador de letalidade afere a letalidade das instituições e o uso abusivo do poder das forças de segurança. Segundo os especialistas em segurança pública, $10 \%$ de mortes provocadas por policiais já é um indicador bastante grave de uso extremamente abusivo do poder (SARMENTO et al., 2019, p. 4-5). O que é possível deduzir é que a polícia do Estado do Rio é extremamente violenta.

Se por um lado a lógica do combate vitimiza civis, sobretudo homens negros e jovens, por outro, a polícia também sucumbe à política do confronto. Apenas no ano de 2018, 89 policiais foram mortos em serviço ou não. Esse número corresponde a $26 \%$ do total de mortes da categoria no país. (SARMENTO et al., 2019, p. 6).

Declarada a pandemia pela Organização Mundial da Saúde, em 11 de março de 2020 (UNA-SUS, 2020), o número de operações policiais diminuiu, segundo a Rede de Observatórios da Segurança. Essas operações, contudo, foram retomadas em abril e maio de 2020, com aumento da letalidade policial se comparado ao mesmo período do ano anterior (RAMOS; PAIVA; NUNES, 2020).

As operações tinham como escopo fundamental o combate ao tráfico de drogas. "Em maio, o levantamento até o dia 19 mostra que o número de operações foi igual ao do ano anterior. Nos três meses, foram monitoradas 120 operações policiais e 36 ações de combate ao coronavírus" (REDE DE OBSERVATÓRIOS DA SEGURANÇA, 2020).

O que se depreende desses dados é que o Estado do Rio empenhou mais força e investimento em políticas de segurança que resultam na morte e na alta letalidade policial do que nas ações de prevenção e combate ao novo coronavírus, focalizadas na saúde. Trata-se de um modelo de Estado que viola direitos sistematicamente e adota a gestão de recursos públicos baseada nos interesses dominantes dos atores políticos, especialmente os personagens eleitorais. 
Fica evidente, portanto, que existe desequilíbrio e desintegração na gestão e na implementação de políticas pública de segurança, correspondendo a um dos problemas de maior impacto social na contemporaneidade, nesse contexto. Revela-se um quadro de descaso e ataque contra as vidas das pessoas moradoras dessas regiões periféricas e pobres.

A ADPF mencionada já tratava da situação de alta mortalidade no Estado e foi protocolada anteriormente à pandemia. Portanto, já havia discussão da matéria no âmbito do STF antes da declaração do estado de emergência no Estado do Rio. Com a pandemia do Covid-19, a situação apenas se agudizou, porque além dos efeitos naturais decorrentes de uma circunstância pandêmica, a polícia, com anuência e estímulo do governador, continuava empreendendo operações com resultados desastrosos.

Duas operações em particular motivaram a tutela provisória, quais sejam: a chacina no Complexo do Alemão e o homicídio de mais uma criança, João Pedro Mattos Pinto, 14 anos de idade, em São Gonçalo (SUPREMO TRIBUNAL FEDERAL, 2020). Diante disso, os peticionários requereram a proibição de novas operações policiais em comunidades enquanto durasse a pandemia de Covid-19, exceto em situações excepcionalíssimas devidamente justificadas pela autoridade competente e com comunicação imediata ao Ministério Público, que tem atribuição constitucional de controle externo da Polícia Militar.

O Min. Relator da ADPF 635, Edson Fachin, no dia 5 de junho de 2020, deferiu a liminar para impedir novas incursões militares em comunidades do estado do Rio, sob pena de responsabilização civil e criminal, salvo em situações excepcionais, conforme requerido pelo peticionário e nos casos de extraordinária necessidade de intervenção policial, as autoridade devem tomar especial cuidado para não interromper a prestação de serviços públicos sanitários e o desempenho de ajuda humanitária. (SUPREMO TRIBUNAL FEDERAL, 2020).

Contudo, no dia 26 de agosto uma operação no Complexo do São Carlos, no Rio de Janeiro, foi empreendida pela Polícia Militar. Supostamente, a inteligência da polícia civil teria a informação que 10 criminosos de comunidades vizinhas estariam disputando o controle do tráfico no São Carlos. (RIBEIRO, 2020). 
Em e-mail enviado ao Ministério Público do Rio de Janeiro pelo Serviço de Atendimento ao Cidadão, questionamos a operação se autorizada por escrito, dada a liminar do STF, proibindo a incursão policial no Rio de Janeiro. Em resposta, a assessoria executiva aduziu:

\begin{abstract}
Em relação ao crime de homicídio que vitimou ANA CRISTINA DA SILVA, ocorrido no dia 26 de agosto de 2020, foi instaurado o IP no 901-00872/2020, pela DH da Capital, de atribuição da $1^{a}$ Promotoria de Justiça de Investigação Penal Especializada do Núcleo Rio de Janeiro - Sede Centro. Providências relacionadas ao referido inquérito foram adotadas, ainda, no âmbito do Processo (Inquérito) no 0171637-16.2020.8.19.0001, em trâmite perante a $3^{a}$ Vara Criminal da Comarca da Capital do Estado do Rio De Janeiro (Protocolo no 20200830-1599201). (BOTELHO, 2020).
\end{abstract}

Não obtivemos, portanto, êxito quanto à validade ou não da operação empreendida, apenas da abertura de inquérito policial para investigar a morte de Ana Cristina da Silva, que foi atingida por tiros de fuzil no bairro do Rio Comprido. (MULHER, 2020).

Ainda sobre o investimento em segurança pública, segundo pesquisa realizada pela Rede de Observatórios da Segurança, $26 \%$ dos 80,6 bilhões previstos para o orçamento de 2020 serão destinados à segurança pública. O Rio de Janeiro é o Estado da federação que mais empenha recursos na área proporcionalmente ao seu orçamento, sobretudo no policiamento ostensivo. O que decorre dessa lógica de investimento, porém, é o maior número de confrontos e, por consequência, maior número de mortes de policiais e civis. (CICONELLO, 2019).

O mote desse investimento é a famigerada guerra às drogas com uso massivo da força policial militar. Segundo a Rede de Observatórios de Segurança (2020, p. 4), em $72,7 \%$ dos casos, a polícia militar é a principal força empregada. Isso demonstra uma faceta cruel, porquanto essa força extremamente militarizada é responsável pelo policiamento ostensivo e não investigativo. Dessa forma, prende-se muito em flagrante delito e não se desmantela efetivamente o crime organizado.

O modelo de segurança pública militarizado e lastreado no confronto, notadamente na guerra as drogas, não é um fenômeno novo, muito pelo contrário. Passa-se a uma breve análise dessa falaciosa guerra.

\title{
3 A GUERRA ÀS DROGAS COMO ANTIGA TECNOLOGIA DE MORTE
}


Segundo informações da Rede de Observatórios de Segurança (2020), nos três meses seguintes à declaração da pandemia pela ONU (abril, maio e junho), foram empreendidas 120 operações policiais contra o tráfico de drogas e 36 de combate ao coronavírus. Sequer uma situação pandêmica que flagrantemente já vitimava moradores de regiões periféricas do Rio, o governo Witzel não deu trégua ao que se denomina "guerra às drogas".

Essas mesmas áreas são as mais violentadas pelo Estado pela deficiência na saúde e na segurança públicas. A Agência Pública (MUNIZ; FONSECA; PINHA, 2020), em relatório divulgado em 6 de maio do ano corrente, aduz que o bairro onde residem mais negros é também a área com maior letalidade por COVID. Campo Grande, bairro periférico na zona oeste do município, concentra 38 mortes contra 12 no Recreio dos Bandeirantes.

Consoante o mesmo relatório, os especialistas não apontam a cor da pele como fator de risco, contudo, segundo Rita Borret, da Sociedade Brasileira de Medicina da Família e Comunidade, a população negra depende mais do Sistema Único de Saúde fortemente precarizado. Além disso, é essa a mesma parcela que menos consegue ficar em isolamento social. (MUNIZ; FONSECA; PINHA, 2020).

Destarte, tanto a violência policial quanto 0 vírus aumentam consideravelmente as taxas de letalidade de corpos negros. Essa violência policial do estado sempre justificada pelo antigo discurso da guerra às drogas. Note que admitir o uso do termo "guerra" é um recurso semiótico ${ }^{2}$ interessante: se há guerra, há, como decorrência lógica, um inimigo e mortes. Naturaliza-se, portanto, a atuação truculenta da polícia militar em áreas pobres e contra pobres.

Segundo Morellato e Santos (2020, p. 712):

[...] a eleição de um inimigo - os traficantes 'favelados' - baseada na ideologia da guerra às drogas tem se mostrado um recurso hábil para legitimar o direcionamento de políticas genocidas à população jovem, negra e periférica em favor da produção de uma sensação de segurança. (MORELLATO; SANTOS, 2020, p. 712).

2 "[...] a Semiótica pode ser entendida como a ciência de todas as linguagens possíveis, pois, diferentemente da Linguística, que se dedica ao estudo do sistema sígnico da linguagem verbal, a Semiótica considera qualquer fenômeno como um sistema sígnico de produção de sentido" (BARROS; CAFÉ, 2012). 
A famigerada guerra às drogas, segundo Boiteux e Lemgruber (2014, p. 358), importada de uma política norte americana nos anos de 1970, se por um lado, ocasionou o encarceramento em massa no mundo, por outro lado, nunca interrompeu a disponibilidade de substâncias. Ademais, outras drogas que provocam danos mais severos, como o álcool e o tabaco, não sofrem a mesma restrição.

A Lei 11.343 de 2006 (BRASIL, 2006), que despenalizou a conduta da posse para uso pessoal de drogas, implicou no aumento do número de presos no país por tráfico de drogas, além de dar uma alta margem para a arbitrariedade policial. Isso porque a distinção entre usuário e traficante é levada a efeito, entre outros critérios, pela elementar "circunstâncias sociais e pessoais" ${ }^{3}$, o que redunda na condenação por tráfico de jovens negros e periféricos. (BOITEUX; LEMGRUBER, 2014, p. 360).

Portanto, é evidente, diante desse quadro, que a guerra as drogas não surtiu os efeitos declaradamente desejáveis: o fim do tráfico e do uso de substâncias ilícitas. Contudo, ainda se persiste nessa lógica com investimento maciço na polícia militar e nas operações policiais.

Dessa forma, surge uma constatação fundamental: a guerra às drogas é uma tecnologia de necropolítica, isto é, ela existe não para enfrentar o uso abusivo de substâncias ou a venda ilegal delas, mas antes para determinar a morte de parcela da população, notadamente preta e pobre, eleger pessoas que encampem o discurso de guerra, a exemplo do governador do Rio de Janeiro, Wilson Witzel, e determinar o uso dos recursos públicos para quem efetivamente interessa.

\section{A NECROPOLÍTICA}

A necropolítica é um conceito pensado pelo filósofo Achille Mbembe a partir do conceito de biopoder do Foucault. Segundo aquele, "[...] o biopoder parece funcionar mediante a divisão entre as pessoas que devem viver e devem morrer [...] tal poder se define em relação a um campo biológico" (MBEMBE, 2018, p. 17). Fundamental para essa divisão é o racismo, tecnologia basilar para o exercício do

\footnotetext{
${ }^{3}$ Art. 28, $\S 2^{\circ}$, da Lei 11.343/2006: Para determinar se a droga destinava-se a consumo pessoal, o juiz atenderá à natureza e à quantidade da substância apreendida, ao local e às condições em que se desenvolveu a ação, às circunstâncias sociais e pessoais, bem como à conduta e aos antecedentes do agente (BRASIL, 2006).
} 
biopoder (MBEMBE, 2018, p. 18). Segundo Mbembe (2018, p. 18), "[...] na economia do biopoder, a função do racismo é regular a distribuição da morte e tornar possíveis as funções assassinas do Estado".

O filósofo camaronês, baseia-se no conceito de biopoder e explora sua relação com as noções de soberania e estado de exceção. Segundo Mbembe (2018), o conceito de biopoder não foi suficiente para explicar algumas construções da modernidade. 0 ideal humano de civilização, liberdade, modernidade europeus não foram capazes de explicar as relações de poder engendradas em instituições como na escravidão e, mais modernamente, nos campos de concentração nazistas e na Palestina (MBEMBE, 2018).

A escravidão e os campos de concentração nazista são a expressão máxima de condição inumana. Em razão da ausência de estatuto político, o estado de exceção foi perenemente invocado e a soberania do Estado exercida plenamente, determinando a morte a partir da raça.

Nota-se que a soberania, bem como o estado de exceção perdem a noção costumeira dada pela ciência política ou mesmo o Direito. A soberania é, em tese, "[...] a produção de normas gerais por um corpo (povo), composto por homens e mulheres. Esses homens e mulheres são considerados livres e iguais" (MBEMBE, 2018, p. 9).

Contudo, a leitura política da soberania não corresponde às formas de dominação e aniquilamento de determinados corpos. Dessa forma, soberania é antes, portanto, a determinação política dos que devem morrer, isto é, o direito de matar exercido pelo estado a partir da invocação de um estado de exceção, que é perene, e inimigos ficcionais (MBEMBE, 2018, p. 16-17).

Nota-se, como revogação do Estado de Direito e a invocação falaciosa de um inimigo, notadamente, no Brasil, o tráfico de drogas, a ser combatido viabilizam o estado de anomia e a condição de não-humanos que podem-devem ser exterminados, porque esses oferecem perigo material e moral à vida da sociedade.

Segundo Mbembe (2018, p. 20-21), as premissas do estado nazista podem ser encontradas no imperialismo colonial, porquanto ao escravizado era negado a humanidade. A condição de escravizado implicava em uma tripla perda: perda do lar, perda dos direitos sobre o corpo e perda do estatuto político (MBEMBE, 2018, p. 27). "A vida do escravo, em muitos aspectos, é uma forma de morte-em-vida" (MBEMBE, 2018, p. 27). 
Mais modernamente, Mbembe (2018) traça um importante comparativo entre o imperialismo colonial e as tardias formas de colonização na Palestina com uso abusivo das tecnologias. Uma importante distinção deve ser traçada: na ocupação colonial, o colonizador apreendia, demarcava e afirmava o controle físico e geográfico, inscrevendo naquele espaço novas relações sociais e espaciais (MBEMBE, 2018, p. 38). O objetivo era relegar o colonizado a um espaço de não-sujeito.

Na Palestina, a necropolítica se revela na segregação racial e social, na formação de entidades sociopolítica, cultural e econômica, a exemplo do que ocorreu no regime do apartheid na África do Sul (MBEMBE, 2018, p. 39-40). No Brasil, notadamente no Rio de Janeiro, as favelas são a grande expressão da segregação racial e social, da formação dessas entidades sociopolíticas, portanto.

O resultado imediato dessa segregação é a restrição à produção dos negros para o mercado de áreas brancas, o controle do fluxo urbano e a criminalização dos espaços negros. Segundo Fanon, citado por Mbembe (2018, p. 41): "A cidade do colonizado [...] é lugar de má fama, povoado por homens de má reputação. Lá eles nascem e pouco importa onde ou como; morrem lá, não importa onde e como."

Note que o Estado não tem pretensão de soberania - no sentido da ciência política do termo - e legitimidade sobre os espaços segregados, ao revés, admitem e alimentam a proliferação de forças paralelas e dos espaços de violência. No Rio de Janeiro, essas forças, supostamente paralelas, a milícia e as redes de tráfico de drogas, disputam o controle comercial do território e invocam também o direito de matar. Há, portanto uma multiplicidade de necropoderes, o Estado e o crime organizado.

Segundo Abdias do Nascimento (2016, p. 100), "No Rio de Janeiro, sofre a população negra a humilhação e a simultânea degradação - das favelas, que se dependuram das encostas dos morros, e por esse motivo se tornam famosas pelo pitoresco de seus barracos e do seu ambiente". E faz uma percuciente constatação "Que tais moradias, imundas, abaixo das necessidades de higiene e conforto humano são habitadas pelo grupo negro é fato bem documentado." (NASCIMENTO, 2016, p. 100).

O controle dos corpos só se faz possível por meio da segregação geográfica e do empenho de recursos altamente tecnológicos. Assim como na Palestina, nas favelas do Rio de Janeiro, a ocupação do espaço aéreo é uma franca demonstração de quem 
tem o poder de observar: "[...] enquanto o helicóptero de combate Apache é usado para patrulhar o ar e matar a partir do céus, o trator blindado bulldozer é usado em terra como arma de guerra e intimidação." (MBEMBE, 2018, p. 48).

$\mathrm{O}$ uso de helicópteros, inclusive, foi alvo de questionamento na ADPF 635. O Art. $2^{\circ}$ do Decreto Estadual no 27.795/2001 (RIO DE JANEIRO, 2001) permite a utilização de helicóptero em confronto armado direto em apoio a operações policiais. Como resultado dessa política de morte, em 2019, as ações policiais se tornaram mais frequentes e mais letais. Foram registradas 222 mortes de janeiro a junho e $68 \%$ resultantes de operações da polícia (REDE DE OBSERVATÓRIOS DE SEGURANÇA, 2019, p. 3).

As mortes provocadas por agentes da segurança pública do Estado representam uma parcela cada vez maior da letalidade violenta registrada no Rio de Janeiro. O mesmo relatório aponta que o uso de helicópteros, se antes era excepcional, no ano de 2019, ele foi utilizado com rigor. De 34 operações monitoradas, em 11 foram usados helicópteros com homens abordo efetuando disparos. "Fazer sobrevoos rasantes sobre áreas de grande densidade populacional e atirar de cima, mesmo sem produzir vítimas, apavora e traumatiza os moradores da área." (REDE DE OBSERVATÓRIOS DE SEGURANÇA, 2019, p. 4-5).

\section{CONCLUSÃO}

Diante do quadro demonstrado pelos peticionários na ADPF 635, não resta dúvida quanto à escolha inequívoca de política de morte pelo Estado de determinadas pessoas, os indesejáveis.

A guerra às drogas não atingiu os efeitos supostamente desejáveis: o fim do tráfico e do uso de substâncias ilícitas. Muito ao revés, a guerra declarada ao tráfico inscreve corpos negros no signo da morte e no encarceramento em massa. 0 perfil dos mortos pela alta letalidade policial são jovens, negros e periféricos, os mesmos que engrossam os números do sistema carcerário.

Note que há uma dupla forma de impor a morte: uma com a extinção da vida propriamente dita e o outro com a imposição de uma morte em vida. 
Se a guerra às drogas, então, não surtiu os efeitos desejados, por que a insistência na criminalização de condutas relacionadas à venda e distribuição de drogas? Aqui uma conclusão inexorável, a guerra às drogas existe enquanto projeto de morte. Não é resultado de uma escolha política atabalhoada, ao revés, é um projeto de extinção da vida daqueles que não são explorados nos subempregos da informalidade neoliberal.

A guerra às drogas produz a segregação e controle dos corpos aos espaços precarizados e criminalizados. Quando desejável pelas elites, essa mesma parcela da população é explorada, quando não, são mortos, seja pelo confronto policial seja pelo "deixar viver ou morrer" pela precarização do sistema único de saúde, notadamente nos últimos meses com a pandemia do coronavírus.

Aliás, a pandemia de escancarou a escolha inequívoca pela morte. $\mathrm{O}$ que se verificou é que houve mais incursão policial contra o tráfico e pouquíssimas operações de enfrentamento ao vírus. Isso nada mais é que a necropolítica.

Sequer a liminar do Min. Fachin impediu novas operações no Rio de Janeiro. A operação policial levada a efeito no Complexo do São Carlos vitimou uma mulher com tiros de fuzil. Em resposta, o Ministério Público do Estado apenas informou que a morte estava sendo investigada, mas quedou-se silente quando à imprescindibilidade da operação.

O que se deduz desse silêncio eloquente é que situações excepcionalíssimas, como aduziu o Min. Edson Fachin, é qualquer situação que justifique o uso massivo das armas da polícia militar e a morte de mais uma que vira estatística.

\section{REFERÊNCIAS}

BARROS, Camila Monteiro de; CAFÉ, Lígia Maria Arruda. Estudos da Semiótica na Ciência da Informação: relatos de interdisciplinaridades. Perspectivas em Ciência da Informação, Belo Horizonte, v. 17, n. 3, p. 18-33, set. 2012 . Disponível em: http://www.scielo.br/scielo.php?script=sci_arttext\&pid=S141399362012000300003\&lng=en\&nrm=iso. Acesso em: 14 set. 2020.

BOITEUX, Luciana; LEMGRUBER, Julita. O fracasso da guerra às drogas. In: LIMA, Renato Sérgio de; RATTON, Luiz José; AZEVEDO, Rodrigo Ghiringhelli de (org.).

Crime, polícia e justiça no Brasil. São Paulo: Contexto, 2014. p. 357-362. 
BOTELHO, Larissa Gabriela Cruz. [E-mail enviado ao Ministério Público]. Destinatário: Ministério Público do Rio de Janeiro. Rio de Janeiro, 30 ago. 2020. 1 email. Disponível em: lari_gcb@hotmail.com. Acesso em: 8 out. 2020.

BRASIL. Lei n. ${ }^{0}$ 11.343, de 23 de agosto de 2006. Institui o Sistema Nacional de Políticas Públicas sobre Drogas - Sisnad; prescreve medidas para prevenção do uso indevido, atenção e reinserção social de usuários e dependentes de drogas; estabelece normas para repressão à produção não autorizada e ao tráfico ilícito de drogas; define crimes e dá outras providências. Brasília, DF: Presidência da República, 2006. Disponível em: http://www.planalto.gov.br/ccivil_03/_ato20042006/2006/lei/l11343.htm. Acesso em: 14 set. 2020.

CICONELLO, Alexandre. A política de segurança pública do Rio de Janeiro é ineficiente e financeiramente insustentável. [Rio de Janeiro]: Rede de Observatórios da Segurança/CESeC, 2019. p. 3. Disponível em:

http://observatorioseguranca.com.br/wpcontent/uploads/2019/12/RELATORIO_REDE-DE-OBS_alexandreciconello_191211_capaBR.pdf. Acesso em: 21 ago. 2020.

FANON, Frantz. Os condenados da Terra. Juiz de Fora, MG: Editora UFJF, 2010. MBEMBE, Achille. Necropolítica. 3. ed. São Paulo: N-1 edições, 2018.

MORELLATO, Ana Carolina Batista; SANTOS, André Filipe Pereira Reid dos. A intervenção federal e a guerra contra os pobres na cidade do Rio de Janeiro.

Dilemas: Revista de Estudos de Conflito e Controle Social, Rio de Janeiro, v. 13, n. 3, p. 711-736, set./dez. 2020. Disponível em: https://revistas.ufrj.br/index.php/dilemas/article/view/23016. Acesso em: 21 ago. 2020.

MULHER morre após ser baleada ao proteger o filho no Complexo do São Carlos. 0 Globo, Rio de janeiro, 27 de agosto de 2020. Disponível em:

https://oglobo.globo.com/rio/mulher-morre-apos-ser-baleada-ao-proteger-filho-nocomplexo-do-sao-carlos-1-24608763. Acesso em: 14 set. 2020.

MULLER, Pierre. As políticas públicas. Tradução: Carla Vicentini. Niterói: EdUFF, 2018.

MUNIZ, Bianca; FONSECA, Bruno; PINHA, Rute. Em duas semanas, o número de negros mortos por coronavírus é cinco vezes maior no Brasil. Pública, [S. I.], 6 de maio de 2020. Disponível em: https://apublica.org/2020/05/em-duas-semanasnumero-de-negros-mortos-por-coronavirus-e-cinco-vezes-maior-no-brasil/\#Link2. Acesso em: 14 set. 2020.

NASCIMENTO. Abdias do. 0 genocídio do negro brasileiro: processo de um racismo mascarado. 3 ed. São Paulo: Perspectivas, 2016. 
RAMOS, Silvia; PAIVA, Anabela; NUNES, Pablo. Máquina de matar. Rede de Observatórios da Segurança, [S. I.], 26 de maio de 2020. Disponível em: http://observatorioseguranca.com.br/category/violencia-por-agentes-do-estado/. Acesso em: 12 ago. 2020.

REDE DE OBSERVATÓRIOS DE SEGURANÇA. Operações policiais no Rio: mais frequentes, mais letais, mais assustadoras. [Rio de Janeiro]: Rede Observatórios da segurança, 2019. Disponível em: http://observatorioseguranca.com.br/wp-content/uploads/2019/07/Novopadr\%C3\%A3o-opera\%C3\%A7\%C3\%B5es-policiais_FINAL_08_07_19.docx.pdf. Acesso em: 27 set. 2020.

REDE DE OBSERVATÓRIOS DE SEGURANÇA. Operações policiais no RJ durante a Pandemia: frequentes e ainda mais letais. [Rio de Janeiro]: Rede Observatórios da segurança, [2020]. Disponível em: http://observatorioseguranca.com.br/wp-content/uploads/2020/05/ Operac\%CC\%A70\%CC\%83es-policiais-no-RJ-durante-a-pandemia.pdf. Acesso em: 12 ago. 2020.

RIBEIRO, L. Criminosos saíram de 10 favelas do Rio para tentar invadir Complexo do São Carlos, diz investigação. G1, Rio de Janeiro, 2020. Disponível em: https://g1.globo.com/rj/rio-de-janeiro/noticia/2020/08/27/criminosos-sairam-de-10favelas-do-rio-para-tentar-invadir-complexo-do-sao-carlos-diz-investigacao.ghtml. Acesso em: 27 ago. 2020.

RIO DE JANEIRO (Estado). Decreto n.0 27.795, de 23 de janeiro de 2001. Acresce e altera dispositivos do decreto no 20.557, de 26 de setembro de 1994, e dá outras providências. Rio de Janeiro, RJ: Governo do Estado do Rio de Janeiro, 2001. Disponível em: https://gov-rj.jusbrasil.com.br/legislacao/226546/decreto-27795-01. Acesso em: 12 ago. 2020.

RIO DE JANEIRO (Estado). Decreto no 46.775, de 23 de setembro de 2019. Altera o decreto n ${ }^{\circ} 41.931$, de 25 de junho de 2009, e dá outras providências. Rio de Janeiro, RJ: Governo do Estado do Rio de Janeiro, 2019. Disponível em:

http://www.fazenda.rj.gov.br/sefaz/content/conn/UCMServer/path/Contribution\%20F olders/site_fazenda/Subportais/PortalGestaoPessoas/Legisla\%C3\%A7\%C3\%B5es\%2 OSILEP/Legisla\%C3\%A7\%C3\%B5es/2019/Decretos/DECRETO\%20N\%C2\%BA\%2046 .775\%20DE\%2023\%20DE\%20SETEMBRO\%20DE\%202019_Altera\%20o\%20Decreto \%20n\%C2\%BA\%2041.931\%20de\%2025\%20de\%20junho\%20de\%202009.pdf? Acesso em: 27 set. 2020.

SARMENTO, D. et al. Arguição de descumprimento de preceito fundamental com pedido de medida liminar. Rio de Janeiro: Brasília, DF: PSB, 2019. Disponível em:

http://redir.stf.jus.br/estfvisualizadorpub/jsp/consultarprocessoeletronico/ConsultarPr ocessoEletronico.jsf?seqobjetoincidente=5816502. Acesso em: 12 ago. 2020. 
SUPREMO TRIBUNAL FEDERAL. Tutela provisória incidental na medida cautelar na Arguição de Descumprimento de Preceito Fundamental 635 Rio de Janeiro. Recorrente: Partido Socialista Brasileiro - PSB. Recorrido: Estado do Rio de Janeiro. Relator: Min. Edson Fachin, 5 de junho de 2020. Disponível em: http://redir.stf.jus.br/estfvisualizadorpub/jsp/consultarprocessoeletronico/ConsultarPr ocessoEletronico.jsf?seqobjetoincidente $=5816502$. Acesso em: Acesso em: 12 ago. 2020.

UNA-SUS. Organização Mundial de Saúde declara pandemia do novo Coronavírus. Portal UNA-SUS, [S. I.], 11 de março de 2020. Disponível em: https://www.unasus.gov.br/ noticia/organizacao-mundial-de-saude-declara-pandemi a-de-coronavirus. Acesso em: 21 ago. 2020. 